For submission to Journal of Environmental Radioactivity

\title{
Short-term accumulation and elimination of carbon-14 in the common carp Cyprinus carpio under laboratory conditions
}

Souloumiac Audrey ${ }^{1}$, Camilleri Virginie ${ }^{1}$, Cavalié Isabelle $^{1}$, Ciffroy Philippe $^{2}$ and Alonzo Frédéric ${ }^{1, *}$

${ }^{1}$ LECO, IRSN, PSE-ENV, SRTE, Cadarache, BP3, 13115 Saint-Paul-lez-Durance, France

${ }^{2}$ EDF, Division Recherche et Développement, Laboratoire National d'Hydraulique et Environnement, 6 quai Watier, 78401 Chatou, France

* corresponding author: frederic.alonzo@irsn.fr 


\begin{abstract}
This study examined the short term transfer of carbon-14 $\left({ }^{14} \mathrm{C}\right)$ in the common carp Cyprinus carpio under laboratory conditions. Various experiments were achieved in order to investigate direct or trophic transfer for 4 days, using waterborne ${ }^{14} \mathrm{C}$-labelled arginine or ${ }^{14} \mathrm{C}$-labelled food pellets respectively. Radiolabelled food was prepared with ${ }^{14} \mathrm{C}$-labelled arginine or glucose in order to test how transfer kinetics might vary with the biochemical form of ${ }^{14} \mathrm{C}$. Elimination experiments were achieved using fish fed for 5 days on radiolabelled food and then placed under starvation for 4 days. In all experiments, water, food and fish activities were monitored every day. Different fish fractions (whole body, muscle) were sampled in order to elucidate the role of muscle as a potential storage. Results suggested that direct water-to-fish absorption rate was $20 \% \mathrm{~d}^{-1}$ per fish. Carps incorporated $14.3 \%$ of the absorbed ${ }^{14} \mathrm{C}$. Fish activity did not increase over days, due to a strong decrease in ${ }^{14} \mathrm{C}$ concentration in the water (resulting from aquarium sorption). During trophic transfer experiments, food was entirely ingested and ${ }^{14} \mathrm{C}$ sources rapidly assimilated. For either arginine or glucose, results suggested that $19-20 \%$ of ingested ${ }^{14} \mathrm{C}$ was incorporated, yielding a significant increase in fish activity over days. No difference in mass-specific activity was observed among muscle and whole body. Total activity in the muscle represented $29 \%-32 \%$ of whole body activity, this proportion reflecting the contribution of muscle to whole body weight. During elimination experiments, results showed a significant decrease in whole body total activity and massspecific activity with arginine. The decrease was not significant with glucose due to a great variability among fish. Results suggested that an essential amino-acid like arginine can be used as an energy source under starvation and that muscles can act as a storage for essential amino-acids.
\end{abstract}

Keywords: ${ }^{14} \mathrm{C}$ transfer kinetics; freshwater fish; arginine and glucose metabolism. 


\section{Introduction}

The radioactive isotope ${ }^{14} \mathrm{C}$, also known as carbon-14 or $\mathrm{C}-14$, is present in the environment as an infinitesimal proportion $\left(10^{-12}\right)$ of total carbon. In fact, carbon is almost entirely represented by its two stable isotopes, ${ }^{12} \mathrm{C}$ and ${ }^{13} \mathrm{C}$, contributing 98.9 and $1.1 \%$ of the total respectively. The main source of ${ }^{14} \mathrm{C}$ in the environment is natural, resulting from the reaction of cosmic neutrons with nitrogen atoms in the high atmosphere. The atmospheric pool of natural ${ }^{14} \mathrm{C}$ is estimated at $1.4 \times 10^{17} \mathrm{~Bq}$, with a half-life of 5730 years and a production rate of $1.4 \mathrm{x}$ $10^{15} \mathrm{~Bq}$ per year (UNSCEAR, 2008). However, ${ }^{14} \mathrm{C}$ also has several anthropogenic origins. First, nuclear weapon testing caused a rapid doubling of ${ }^{14} \mathrm{C}$ proportion in all environmental compartments during the second half of the $20^{\text {th }}$ century. This proportion gradually decreased after the end of testing, to return to its initial level during the 2010 decade (McGee et al., 2004; Otlet et al., 1997; Roussel-Debet et al., 2006; Roussel-Debet, 2014). Second, ${ }^{14} \mathrm{C}$ is the radionuclide released in greatest amount by nuclear reprocessing plants and nuclear power plants (NPP) in normal operation (Florence \& Hartmann, 2003; Garnier-Laplace et al., 2009). In France for example, an average activity from 1.5 to $3.0 \times 10^{11} \mathrm{~Bq}$ is released every year by a pressurized water reactor (Florence \& Hartmann, 2003). A major part of this radioactivity (approximately $85-95 \%$ ) is released into the atmosphere as $\mathrm{CO}_{2}$ and $\mathrm{CH}_{4}$, while $5-15 \%$ is released into the rivers as dissolved $\mathrm{CO}_{2}$ with liquid effluents (EDF, 2014).

Following the cycle of carbon, both anthropogenic and natural ${ }^{14} \mathrm{CO}_{2}$ enter aquatic food webs through photosynthesis and primary production and are transferred towards higher trophic levels. In order to assess the consequences for the environment and for human health, transfer models are used to predict ${ }^{14} \mathrm{C}$ activity in fish and the associated dose for human consumers, based on average amounts released over the year (Avetisov et al., 2001; Boyer \& BeaugelinSeiller, 2002; Galeriu et al., 2007; Le Dizès et al., 2012). These models assume that ${ }^{14} \mathrm{C}$ behaviour is similar to that of stable carbon and that a common isotopic ratio is shared among water and aquatic organisms. Predictions suggest that anthropogenic ${ }^{14} \mathrm{C}$ is the main contributor to the absorbed dose of $1 \mu \mathrm{Sv}$ per year, approximately estimated for generic fish consumers living in the vicinity of NPP (Mourlon \& Vermorel, 2014; Siclet, 2001; Siclet et al., 2002; UNSCEAR, 2000). This should be noted that this dose remains largely lower than the annual legal limit of $1 \mathrm{mSv}$ per year for the public. However, the estimated dose is calculated for equilibrium ${ }^{14} \mathrm{C}$ concentrations and does not consider time variations observed in the field. In 
fact, aquatic discharges by NPP generally occur 2 or 3 times per month, depending on operating requirements, causing a temporal variability in ${ }^{14} \mathrm{C}$ activity in the water (Siclet et al., 2002). As a result, mass-specific ${ }^{14} \mathrm{C}$ activity shows a greater variability over time in water in the aquatic systems than in the terrestrial environments, with bicarbonate varying from 150 to $250 \mathrm{~Bq}{ }^{14} \mathrm{C}$ per kg C (Florence \& Hartmann, 2003). Finally, mass-specific ${ }^{14} \mathrm{C}$ activities in fish range from $200-240 \mathrm{~Bq}{ }^{14} \mathrm{C}$ per $\mathrm{kg} \mathrm{C}$ (in areas outside NPP influence) to $300-1000 \mathrm{~Bq}{ }^{14} \mathrm{C}$ per $\mathrm{kg} \mathrm{C}$ (in areas under NPP influence), but this variability is not clearly understood (EDF, 2014).

In order to address variations in ${ }^{14} \mathrm{C}$ concentrations in the water over time, dynamic transfer models have been established (Sheppard et al., 2006; Smith, 2006). However, these models do not take account of differences in fish physiology among species (ingestion rate, growth rates, etc.) varying with age and with environmental factors such as temperature or resource availability. In this context, physiology-based models such as those based on the Dynamic Energy Budget (DEB) Theory (Kooijman, 2010) appear as an interesting alternative. For more than two decades, DEB models have been used to describe, in a generic way, how organisms take their energy from food and allocate it to major biological functions in a growing range of animal species (Add-my-pet collection, 2018). This modelling approach offers a unique conceptual framework to predict time-varying metabolic responses as a function of temperature and food (Kooijman, 2010). One particularly interesting extension of the DEB theory, the Dynamic Isotope Budget (DIB) model (Pecquerie et al., 2010) was developed to study the fluxes of $\mathrm{C}, \mathrm{N}, \mathrm{H}$ and $\mathrm{O}$ isotopes within organisms. DIB models are used to analyse the composition in stable isotopes $\left({ }^{13} \mathrm{C}\right.$ and $\left.{ }^{15} \mathrm{~N}\right)$, which reflects species trophic position in food webs. The approach, which was applied to ${ }^{13} \mathrm{C}$ and ${ }^{15} \mathrm{~N}$ in the pacific oyster Crassosteas gigas only (Emmery et al., 2011), might be highly useful to predict ${ }^{14} \mathrm{C}$ transfer in aquatic organisms. The approach requires adequate experimental data which are too scarce in the literature. In this context, the present study aims to investigate direct and trophic ${ }^{14} \mathrm{C}$ transfer in the common carp Cyprinus carpio, as a representative species inhabiting French rivers. Furthermore, accumulation and elimination kinetics might vary depending on the biochemical form of ${ }^{14} \mathrm{C}$ and this hypothesis is tested using various ${ }^{14} \mathrm{C}$ sources, including arginine (an essential amino acid for carps) and glucose (an important source of energy in a majority of animal species) (Bouche \& Vellas, 1975; Murai et al., 1986; Nagai \& Ikeda, 1971a, 1971b; Ranson, 2003).

\section{Materials and methods}




\subsection{Fish maintenance}

Juvenile common carps (Cyprinus carpio) were obtained from Saint-Julitte fish farm (SaintFlovier, France). Fish were kept in the laboratory in $400 \mathrm{~L}$-tanks. Water was maintained at $18^{\circ} \mathrm{C}$ $\left( \pm 1^{\circ} \mathrm{C}\right)$, in agreement with average temperature in La Vienne river (France), continuously oxygenated and filtered, and partly renewed (50\%) every day. Water quality was monitored on a daily basis ( $\mathrm{pH}=8$ and nitrite concentration $<50 \mathrm{mg} \mathrm{L}^{-1}$ ). Fish were fed at a daily ratio of $3 \%$ w/w with sinking food pellets for carps («T-Etang » 5-mm pellets, composition in SI Table S1) purchased from Le Gouessant (Lamballe, France).

Before experiments, carps were acclimated to experimental conditions for 3 weeks. Each carp was kept in an individual aquarium of $8 \mathrm{~L}$ and fed a daily ration of $0.3 \mathrm{~g}$ per fish. Water was maintained at $18^{\circ} \mathrm{C}\left( \pm 1^{\circ} \mathrm{C}\right)$, oxygenated with constant air bubbling and partly renewed $(20 \%)$ every day.

\subsection{Food contamination and desorption}

${ }^{14} \mathrm{C}$-labelled solutions of arginine and glucose (arginine L- $\left[{ }^{14} \mathrm{C}(\mathrm{U})\right]$ and glucose D- $\left[{ }^{14} \mathrm{C}(\mathrm{U})\right]$, 97\% purity, $1.85 \mathrm{MBq}$ ) were purchased from PerkinElmer (Courtaboeuf, France). ${ }^{14} \mathrm{C}$-Arginine and ${ }^{14} \mathrm{C}$-Glucose were stored at $4{ }^{\circ} \mathrm{C}$ in ethanol solutions of $2 \%$ and $90 \%$ respectively. Radiolabelled food was prepared by mixing $15 \mathrm{~g}$ of ground food pellets with $17.7 \mathrm{~mL}$ of UHQ water and $292 \mu \mathrm{L}$ of ${ }^{14} \mathrm{C}$-solution (arginine or glucose). The homogenised mixture was divided into $5-\mathrm{mm}$ pellets which were dried for 2 days at $60 \mathrm{C}$. In order to reduce the potential loss of ${ }^{14} \mathrm{C}$ into water during feeding experiments, radiolabelled food pellets were coated with agaragar (using $0.08 \mathrm{~g}$ of agar in $10 \mathrm{~mL}$ of water) and dried for another 2 days at room temperature. Five samples of $0.1 \mathrm{~g}$ were collected in order to estimate ${ }^{14} \mathrm{C}$ activity in the food by liquid scintillation.

${ }^{14} \mathrm{C}$ desorption from food to water was investigated in order to determine how long radiolabelled food pellets should be left in water during the feeding experiments. To do so, 0.1 $\mathrm{g}$ of ${ }^{14} \mathrm{C}$-labelled food was placed in a vial containing $5 \mathrm{~mL}$ of water. Working with a small volume was necessary to avoid ${ }^{14} \mathrm{C}$ dilution and keep water activity above the detection limit by liquid scintillation. Five replicate vials were used to monitor ${ }^{14} \mathrm{C}$ activity in water after 2, 5, $10,20,30$ and $60 \mathrm{~min}$. Each time, $1 \mathrm{~mL}$ of water was collected from each vial and $1 \mathrm{~mL}$ was added to achieve a volume of $5 \mathrm{~mL}$ again. 


\subsection{Direct transfer experiment}

This experiment aimed to estimate the magnitude of direct water-to-fish ${ }^{14} \mathrm{C}$ transfer. To do so, $30000 \mathrm{~Bq}$ of ${ }^{14} \mathrm{C}$-labelled arginine were added to each aquarium containing a fish in $8 \mathrm{~L}$ of water (yielding a ${ }^{14} \mathrm{C}$ concentration of $3750 \mathrm{~Bq} \mathrm{~L}^{-1}$ on Day 0 ). A solution of ${ }^{14} \mathrm{C}$-labelled arginine at the same concentration was used on Days 1 and 3 , to bring the volume back to $8 \mathrm{~L}$ and compensate water evaporation. Direct absorption was estimated by measuring ${ }^{14} \mathrm{C}$ activity in water and fish after 1, 3 and 4 days. Two fish were collected on each sampling day. Water samples of $1 \mathrm{~mL}$ were collected before and after water addition. Control aquaria were also prepared to monitor the background decline in water activity without fish.

Changes in ${ }^{14} \mathrm{C}$ activity in water were described assuming exponential decay models, with coefficients $k_{f}$ and $k_{b}$ associated with fish absorption and background aquarium sorption. On this basis, ${ }^{14} \mathrm{C}$ concentration $\left[C_{14}\right]_{t}$ in the water at time $t$ was calculated as:

$\left[C_{14}\right]_{t}=\left[C_{14}\right]_{t_{0}} \cdot \exp \left(-k \cdot\left(t-t_{0}\right)\right)$

where $\left[C_{14}\right]_{t_{0}}$ is ${ }^{14} \mathrm{C}$ concentration in the water at time $t_{0}$, and $k=k_{f}+k_{b}$ measured in presence of carps or $k=k_{b}$ measured in control aquaria respectively.

\subsection{Trophic transfer experiments}

Feeding experiments were carried out in order to estimate the magnitude of trophic foodto-fish transfer. Before the beginning of experiments, fish were starved for two days, in order to stimulate food intake. During the feeding experiments, carps were fed for 4 days a daily ration of $0.3 \mathrm{~g}$ per fish using ${ }^{14} \mathrm{C}$-labelled food pellets. Food was left in water for $10 \mathrm{~min}$ maximum, in order to minimize ${ }^{14} \mathrm{C}$ desorption to water and direct absorption by fish. After this time, non-ingested pellets were collected, weighed and analysed by liquid scintillation. In a few cases, fish did not eat their daily ration and were discarded from experiments. Three fish were collected on days 1, 2, 3 and 4 (total of 12 fish). Every day during feeding experiments, faeces were collected and $1 \mathrm{~mL}$ of water was sampled before and after feeding.

Trophic transfer was considered following a succession of processes, including: - ingestion, where a fraction of ${ }^{14} \mathrm{C}$ supplied with food entered fish digestive tracts; - assimilation, where a fraction of ingested ${ }^{14} \mathrm{C}$ entered fish organisms through the intestinal epithelium; 
- incorporation, where the fraction of assimilated ${ }^{14} \mathrm{C}$ became part of the fish body (as opposed to assimilated ${ }^{14} \mathrm{C}$ which was immediately used as an energy source and released as ${ }^{14} \mathrm{CO}_{2}$ within $24 \mathrm{~h}$ ).

\subsection{Elimination experiments}

Elimination experiments aimed to investigate how fast fish might use incorporated ${ }^{14} \mathrm{C}$ as an energy source under starvation. Before experiments, carps were fed for 5 days a daily ration of $0.3 \mathrm{~g}$ per fish using ${ }^{14} \mathrm{C}$-labelled food pellets. At the beginning of experiments, half of the volume was replaced with clean water in order to reduce ${ }^{14} \mathrm{C}$ concentration in the water and direct absorption by fish. During the elimination experiments, carps were starved for 4 days. Three fish were collected on days 2, 3 and 4 (total of 9 fish). Every day during elimination experiments, faeces were collected and $1 \mathrm{~mL}$ of water was sampled in each aquarium.

\subsection{Sample treatments and ${ }^{14} \mathrm{C}$ analyses}

Each carp was euthanized immediately and its body size and wet weight (ww) were measured. Different fractions (muscles, rest of the body) were dissected, weighed and homogenised with a blender. Three replicate samples of $1 \mathrm{~mL}$ approximately were collected from each homogenised fraction. Collected faeces and food samples were dried at $60^{\circ} \mathrm{C}$ overnight. All samples (including water samples of $1 \mathrm{~mL}$ ) were transferred into scintillation vials and weighed.

Mineralisation was achieved at $60^{\circ} \mathrm{C}$ for 2 days, after addition of $1 \mathrm{~mL}$ of $\mathrm{NaOH} 1 \mathrm{M}$ (dried faeces, dried food and water samples) or $5 \mathrm{~mL}$ of $\mathrm{NaOH} 1 \mathrm{M}$ (fish samples). One $\mathrm{mL}$ of each mineralised fish sample was transferred into a new scintillation vial. Mineralised fish, faeces and food samples were diluted with $1 \mathrm{~mL}$ of UHQ water to achieve a final volume of $2 \mathrm{~mL}$. All samples were diluted with $18 \mathrm{~mL}$ of Ultima Gold cocktail (PerkinElmer, Boston, USA) and ${ }^{14} \mathrm{C}$ radioactivity was quantified with a liquid scintillation counter (Quantulus 1220 (WallacPerkinElmer, Finland; detection limit: $30 \mathrm{mBq}$ ).

\subsection{Data analyses}

All statistical analyses were conducted using the statistical computing software R (RStudio, 2020). Two-factor ANOVA and linear regressions were achieved with the routine $l m$. Validity assumptions including errors independence and normality were assessed using Durbin and Watson test and Shapiro test, respectively. Errors homogeneity was assessed using Bartlett test 
(ANOVA) and Breush-Pagan test (linear regression). All analyses were achieved with alpha risks $*<0.05, * *<0.01, * * *<0.001$

\section{Results}

\subsection{Direct ${ }^{14} \mathrm{C}$ transfer from water}

With dissolved radiolabelled arginine, water ${ }^{14} \mathrm{C}$ activity declined significantly over time in all aquaria (Figure 1). The observed decline was significantly stronger in aquaria with fish than in control aquaria (SI Table S2A). Linear regression yielded exponential coefficients $k_{b}=0.260 \pm 0.016 \mathrm{~d}^{-1}$ and $k_{f}+k_{b}=0.552 \pm 0.035 \mathrm{~d}^{-1}$ respectively $(n=24$ and p.c. $<0.001$ in both cases). These results suggested a background sorption rate of $23 \% \mathrm{~d}^{-1}$ and a fish absorption rate of $20 \% \mathrm{~d}^{-1}$. Estimated ${ }^{14} \mathrm{C}$ absorption rate per fish decreased over time, as a result of declining water ${ }^{14} \mathrm{C}$ activity, with average values ranging from $4650 \pm 1040 \mathrm{~Bq} \mathrm{~d}^{-1}$ over 1 day, $3010 \pm 300 \mathrm{~Bq} \mathrm{~d}^{-1}$ over 3 days, to $2600 \pm 150 \mathrm{~Bq} \mathrm{~d}^{-1}$ over 4 days. Cumulated ${ }^{14} \mathrm{C}$ absorption represented total activities per fish of $4550 \pm 1040,9030 \pm 850$ and $10400 \pm 800 \mathrm{~Bq}$ over 1,3 and 4 days respectively.

Whole body total activity ranged from $650 \pm 20$ to $760 \pm 450 \mathrm{~Bq}$ per fish depending on days (Figure 2A, SI Table S2B). Average mass-specific activities in fish, associated with ${ }^{14} \mathrm{C}$ incorporation, varied from $13.6 \pm 0.4 \mathrm{~Bq} \mathrm{~g}^{-1}$ on Day $1,17.7 \pm 11.0 \mathrm{~Bq} \mathrm{~g}^{-1}$ on Day 3, to $19.4 \pm 8.5 \mathrm{~Bq} \mathrm{~g}^{-1}$ on Day 4 (Figure 2B, SI Table S2B). This observed increase over time was not significant, due to a great individual variability among fish. Accumulation of ${ }^{14} \mathrm{C}$ in fish was somehow lessened by the strong decline in arginine concentration observed in water over time. A minor fraction of absorbed ${ }^{14} \mathrm{C}$ was incorporated to fish, decreasing over time from $14.3 \%$ on Day 1 to $7.0 \%$ on Day 4 in the whole body and from $1.9 \%$ on Day 1 to $1.0 \%$ on Day 4 in the muscle. This result suggested that a major fraction of absorbed ${ }^{14} \mathrm{C}$ was likely metabolized and eliminated through respiration and excretion. Interestingly, water-to-fish direct transfer (absorption and incorporation) resulted in transfer factors that increased over time, from 3.9 to 10.9 in whole body and from 1.7 to 4.7 in muscle.

\subsection{Food activity}

Radiolabelled food showed different mass specific activities depending on the ${ }^{14} \mathrm{C}$ source, with values of $\sim 590 \pm 100 \mathrm{~Bq} \mathrm{~g}^{-1}$ with glucose and $5950 \pm 470 \mathrm{~Bq} \mathrm{~g}^{-1}$ with arginine. When food 
pellets were placed in water, activity of dissolved ${ }^{14} \mathrm{C}$ significantly increased in water over time (Figure 3, SI Table S3). This increase was significantly stronger for arginine than for glucose, with average desorption from food representing respectively 37 and $25 \%$ of initial activity after $1 \mathrm{~h}$. On this basis, we decided to remove food pellets from water after 10 min during feeding experiments, in order to minimize direct ${ }^{14} \mathrm{C}$ transfer to fish.

\subsection{Trophic transfer}

Each day, $0.3 \mathrm{~g}$ of radiolabelled food pellets represented an average supply of $1800 \mathrm{~Bq}$ and $180 \mathrm{~Bq}$ per aquarium, with arginine and glucose respectively. As a result, water ${ }^{14} \mathrm{C}$ activity showed a significant increase over time (Figure 4, SI Table S4A), reaching in 4 days maximum values of 1260 and $250 \mathrm{~Bq}$, with both arginine and glucose respectively. Each day, water ${ }^{14} \mathrm{C}$ activity also showed an increase caused by food addition (Figure 4, SI Table S4A). This increase was statistically significant with arginine only, due to a relatively great variability in water activity with glucose. Observed values suggested that $250 \mathrm{~Bq}$ and $50 \mathrm{~Bq}$ approximately desorbed from food during fish feeding. Desorption from food represented $16 \%$ and $26 \%$ of supplied activity, with arginine and glucose respectively.

Most fish fed well on radiolabelled food pellets, with only a slight fraction (less than $3 \%$ ) of supplied food remaining in aquaria after $10 \mathrm{~min}$. Whole body total activity significantly increased over time (Figures 5A and 5C, SI Table S4B). With ${ }^{14} \mathrm{C}$-labelled arginine, average values ranged from $385 \pm 190 \mathrm{~Bq}$ per fish on Day 1 to $1150 \pm 270 \mathrm{~Bq}$ per fish on Day 4 . With ${ }^{14} \mathrm{C}$-labelled glucose, average values increased from $35 \pm 15 \mathrm{~Bq}$ per fish on Day 1 to $105 \pm 20$ $\mathrm{Bq}$ per fish on Day 4. Recorded whole body activity represented $15-16 \%$ of supplied activity in food, and 19-20\% of ingested activity (calculated as supplied activity minus desorption from food). Considering a water absorption rate of $20 \%$ per day and an incorporation rate of $14.3 \%$ (as estimated from direct transfer), observed ${ }^{14} \mathrm{C}$ desorption from food might result in a direct incorporation of 78 and $12 \mathrm{~Bq}$ per fish, with arginine and glucose respectively, approximately estimated over 4 days. These values accounted for minor proportions ( $7 \%$ and $12 \%$ respectively) of the total activity observed in fish.

Muscle total activity similarly increased over time (Figures $5 \mathrm{~A}$ and $5 \mathrm{C}$ ), from $78 \pm 52$ to $330 \pm 250 \mathrm{~Bq}$ with arginine, and from $10 \pm 1.3$ to $34 \pm 5.3 \mathrm{~Bq}$ with glucose. Values represented approximately $29-32 \%$ of whole body total activity, independent of days (SI Table S4B). This proportion reflected the contribution of the muscle to whole body weight (28-29\%). Mass specific activities ( $\mathrm{Bq}$ per $\left.\mathrm{g}^{-1} \mathrm{ww}\right)$ increased over time and did not significantly differ between 
whole body and muscle (Figures 5B and 5D, SI Table S4B). Average values ranged from $7.0 \pm 1.5$ to $32 \pm 5.2 \mathrm{~Bq} \mathrm{~g}^{-1}$ ww with arginine and from $0.5 \pm 0.1$ to $1.7 \pm 0.4 \mathrm{~Bq} \mathrm{~g}^{-1}$ ww with glucose. Associated trophic transfer factors (TTF, as $\mathrm{Bq} \mathrm{g}^{-1}$ ww per $\mathrm{Bq} \mathrm{g} \mathrm{g}^{-1}$ water) increased over time, from $1.3 \%$ on Day 1 to $6.2 \%$ on Day 4 with arginine and from $1.0 \%$ on Day 1 to $3.4 \%$ on Day 4 with glucose.

\subsection{Elimination}

During the preliminary feeding phase, food supply represented a daily activity of $1070 \mathrm{~Bq}$ and $145 \mathrm{~Bq}$, with arginine and glucose respectively, reaching a total over 5 days of $5350 \mathrm{~Bq}$ and $725 \mathrm{~Bq}$ respectively. With arginine, water ${ }^{14} \mathrm{C}$ activity significantly increased over time, from $1520 \mathrm{~Bq}$ on Day 1 to $1950 \mathrm{~Bq}$ on Day 5 (Figure 6A). Due to a large variability in activity with glucose, water ${ }^{14} \mathrm{C}$ activity did not increase significantly over time, varying on average from $350 \mathrm{~Bq}$ to $790 \mathrm{~Bq}$ among days (Figure 6B). At the beginning of the elimination experiments, water ${ }^{14} \mathrm{C}$ activity was diluted by a factor of 2 . With both arginine and glucose, water ${ }^{14} \mathrm{C}$ activity did not vary significantly over time during the elimination phase (Figures $6 \mathrm{~A}$ and $6 \mathrm{~B})$.

With arginine, whole body total activity significantly varied among days of elimination (Figure 7A, SI Table 5), from $2220 \pm 300$ to $1540 \pm 580 \mathrm{~Bq}$ per fish. Value on Day 2 represented $\sim 41 \%$ of ${ }^{14} \mathrm{C}$ activity supplied with food over the 5 days. With glucose, whole body total activity did not significantly decrease over days of elimination, varying from $105 \pm 40$ to $85 \pm 4 \mathrm{~Bq}$ per fish (Figure 7C, SI Table 5). With glucose, whole body total activity represented $\sim 15 \%$ of activity supplied with food, suggesting a much greater ${ }^{14} \mathrm{C}$ incorporation with arginine than with glucose. Again, considering an absorption rate of $20 \%$ per day and an incorporation rate of $14.3 \%$ per day for absorption and incorporation respectively (as estimated from direct transfer), observed water ${ }^{14} \mathrm{C}$ activity might result in a direct incorporation of 220 and $80 \mathrm{~Bq}$ per fish, with arginine and glucose respectively, approximately estimated over 5 days of elimination. These activities accounted for $10 \%$ and $72 \%$ of whole body total activity, and for 4 and $10 \%$ of supplied food activity, with arginine and glucose respectively

Muscle total activity showed no statistically significant change over time (Figures 7A and 7C), with values ranging from $520 \pm 350$ to $930 \pm 240 \mathrm{~Bq}$ with arginine and, from $12 \pm 4.9$ to $25 \pm 9.9 \mathrm{~Bq}$ with glucose. Values represented approximately 34 and $23 \%$ of whole body total activity, for arginine and glucose respectively (SI Table 5). These proportions suggested that glucose was eliminated more rapidly than arginine in the muscle. Mass-specific activities did 
not differ significantly between the muscle and whole body (Figures 7B and 7D, SI Tables 5). With arginine, values varied significantly among days of elimination, from $50 \pm 9.0$ to $26 \pm 17$ $\mathrm{Bq} \mathrm{g}^{-1} \mathrm{ww}$. With glucose, values did not differ significantly among days of elimination, ranging from $0.6 \pm 0.2$ to $1.2 \pm 0.6 \mathrm{~Bq} \mathrm{~g}^{-1}$. Associated trophic transfer factors (TTF) ranged from $7.3 \%$ to $14 \%$ with arginine and from $1.2 \%$ to $2.4 \%$ with glucose. With glucose, estimated TTF values were similar between the elimination and the feeding experiments. With arginine, estimated TTF values were twice greater during the elimination experiment than during the feeding experiment.

\section{Discussion}

Our study addressed ${ }^{14} \mathrm{C}$ accumulation kinetics in C. carpio during short term direct or trophic contamination experiments. Results with ${ }^{14} \mathrm{C}$-labelled arginine showed that carps directly absorbed $20 \%$ of waterborne arginine each day, representing approximately the activity in $1.6 \mathrm{~L}$ of water ( $20 \%$ of $8 \mathrm{~L}$ aquaria). This value was small compared to ventilation volumes expected to be pumped by carps at $18^{\circ} \mathrm{C}$ (Klyszejko et al., 2003), suggesting that transfer efficiency through gill membranes was below 10\%. Results also showed that minor fractions of assimilated ${ }^{14} \mathrm{C}$-labelled arginine (ranging from 14 to $20 \%$ ) were finally incorporated to whole body, implying that a major part was catabolized and released as ${ }^{14} \mathrm{CO}_{2}$ via respiration. This result was in good agreement with previous studies on metabolism of ${ }^{14} \mathrm{C}$-labelled aminoacids (including essential lysine and non-essential glutamate) and glucose in C. carpio (Bouche \& Vellas, 1975; Nagai \& Ikeda, 1971b). Authors reported that a significant fraction (45\%) of glutamate activity injected into blood was released as ${ }^{14} \mathrm{CO}_{2}$ within $6 \mathrm{~h}$, while a minor fraction (7\% only) were stored as hepatic glycerides. Authors further showed that glutamate incorporation varied depending on diet composition, with a similar level of ${ }^{14} \mathrm{CO}_{2}$ production and no ${ }^{14} \mathrm{C}$-labelled glyceride storage when carps were fed on a high carbohydrate food $(90 \%$ starch and $10 \%$ casein). In our study, results suggested that arginine incorporation differed between direct and trophic experiments (14.3 and 18.6\% respectively), suggesting a greater arginine storage when carps were fed than when they were starved. This interpretation was supported by previous results showing that starved carps stopped storing another essential amino-acid $\left({ }^{14} \mathrm{C}\right.$-labelled lysine) (Bouche \& Vellas, 1975). The present study reported approximately similar proportions of incorporation with ${ }^{14} \mathrm{C}$-labelled glucose as with arginine ( $20 \%$ and $19 \%$ of ingested activity), suggesting again that a major fraction of glucose was 
released via respiration or other metabolic paths during trophic experiments. This observation was in good agreement with the recognized limited importance of glucose as energy source in fish (Enes et al., 2009). Other results showed that ${ }^{14} \mathrm{CO}_{2}$ production after $6 \mathrm{~h}$ was much lower with ${ }^{14} \mathrm{C}$-labelled glucose than with ${ }^{14} \mathrm{C}$-labelled glutamate $(15 \%$ and $45 \%$ of activity injected into blood respectively), although no important storage of radiolabelled glycogen (limited to 7 $8 \%$ of injected activity) was observed in fish (Nagai \& Ikeda 1971b).

Our study also addressed ${ }^{14} \mathrm{C}$ elimination kinetics in C. carpio during short term starvation experiments. Results showed that activity of ${ }^{14} \mathrm{C}$-labelled arginine decreased in starved carps, whereas no similar decrease was observed with ${ }^{14} \mathrm{C}$-labelled glucose. This suggested that carps stored arginine under favourable food conditions and were able to mobilize it during starvation, confirming the role of amino-acids (including essential amino-acids, like lysine or arginine) as an energy source (Bouche \& Vellas, 1975; Enes et al., 2009). Other authors pointed the role of muscle as a storage organ for amino-acids in C. carpio. In carps, amino-acids were recognized as a main precursor for lipids, which were seasonally stored in the hepatopancreas during the summer (Kminkova et al., 2001; Nagai \& Ikeda, 1971b). Lipids were mobilized in priority under starvation while carbohydrates were consumed when lipid content in hepatopancreas was depleted (Nagai \& Ikeda, 1971a). Our data on mass-specific activities supported the role of muscle as amino-acid storage, with a greater mass-specific activity in the muscle during feeding experiments than after starvation.

Data reported in the present study aimed to be used to model ${ }^{14} \mathrm{C}$ transfer in an aquatic ecosystem. In the literature, ${ }^{14} \mathrm{C}$ transfer models (Sheppard et al., 2006; Smith, 2006) were based on the common assumption that ${ }^{14} \mathrm{C}$ activity in the various biotic compartments entered the aquatic system through photosynthesis and primary producers only. However, our results showed that highly assimilable nutriments, such as arginine, could directly be absorbed from water, and contribute to a minor fraction of fish ${ }^{14} \mathrm{C}$ intake during feeding experiments $(\sim 10 \%)$. While waterborne nutriments, such as valuable amino-acids, might be most likely kept at extremely low concentrations due to biotic activity in the river, any other assimilable molecules, including xenobiotic contaminants or compounds of the degraded organic matter (Eyrolle et al., 2018; Jean-Baptiste et al., 2019), might also be involved in a direct and trophic ${ }^{14} \mathrm{C}$ transfer to aquatic organisms (Saito et al., 1994; Shimizu et al., 1978; Tjeerdema \& Crosby, 1988; Velisek et al., 2009). 
In dynamic models of aquatic ${ }^{14} \mathrm{C}$ transfer (Sheppard et al., 2006; Smith, 2006), specific activity in fish were assumed to vary over time as a function of ${ }^{14} \mathrm{C}$ intake from food and $\mathrm{C}$ turnover rates measured at an organism or population level. Intake from food was calculated based on food activity, ingestion rate (varying with food availability) and associated assimilation efficiency (or digestibility, i.e. the fraction of ingested food which can enter the organism through the intestinal epithelium). Turnover rates at the organism level included metabolic turnover and dilution by somatic growth. Mortality might also be considered when $\mathrm{C}$ turnover was addressed at the population level. In practice, authors acknowledged that a precise quantification of ingestion, digestion, assimilation and turnover rates were not easy for wild fish and was complicated by the diversity of their trophic positions in natural food webs. As a consequence, model parameterization relied most often on indirect estimation methods. In Smith, (2006), a generic value of assimilation efficiency was estimated for stable carbon using data on growth rates in Brown trout Salmo trutta (Elliott, 1975), assuming that equilibrium among biotic compartments was reached. Long term turnover rates were addressed in a natural lake, by analysing changes in ${ }^{14} \mathrm{C}$ activities over several years (Stephenson et al., 1994), showing that specific activity in fish was much higher than that measured in their food items at the time of sampling. In this context, the present study provided valuable new insights in the short term physiological behaviour of a freshwater fish, showing that rapid fluxes might involve 5 times greater amounts of ${ }^{14} \mathrm{C}$ than measured in fish tissues. This short term dynamics might partially explain the great variability in fish ${ }^{14} \mathrm{C}$ activity observed in samples from radioecological surveys in the French rivers (Duffa et al., 2007).

Addressing both long term and short term changes in ${ }^{14} \mathrm{C}$ activity in a fish might be difficult using a single compartment model (Sheppard et al., 2006; Smith, 2006). Other authors suggested using at least two compartments, one for structural $\mathrm{C}$ and another for temporary storage C (Galeriu et al., 2003), in order to describe more accurately the natural variability in fish activity. Such models were promoted in the framework of the Dynamic Energy Budget theory for several decades (Kooijman, 2010), allowing to mechanistically describe metabolic behaviour of organisms in an increasing range of species in relation with their environment (Add-my-pet collection, 2018). This approach was further extended to address changes in major biogenic elements and their isotopes (Pecquerie et al., 2010). One of our future perspectives should aim to parameterize a DEB model for ${ }^{14} \mathrm{C}$ in common carps using the data presented in the present study. 


\section{Conclusions}

Experimental results showed that common carps can absorb ${ }^{14} \mathrm{C}$-labelled molecules via direct and trophic routes, with different transfer efficiencies depending on feeding condition and biochemical form of ${ }^{14} \mathrm{C}$. A major fraction of absorbed ${ }^{14} \mathrm{C}$ was catabolized and released as ${ }^{14} \mathrm{CO} 2$ on the short term. A minor fraction of ${ }^{14} \mathrm{C}$ was incorporated into organism tissues, contributing to a rapid increase in fish ${ }^{14} \mathrm{C}$ activity. Freshwater ${ }^{14} \mathrm{C}$ transfer models need to consider the influence of ecophysiological conditions on short term ${ }^{14} \mathrm{C}$ kinetics in order to address rapid variations in freshwater fish activity.

\section{References}

Add-my-pet collection. (2018). AmP. www.bio.vu.nl/thb/deb/deblab/add_my_pet/.

Avetisov, G., Barry, P., Beninson, D., \& Vidlakova, J. (2001). Generic models for use in assessing the impact of discharges of radioactive substances to the environnement. Safety Report series, 19. IAEA, Vienna. 216 pp.

Bouche, G., \& Vellas, F. (1975). Les vitesses de renouvellement des proteines hepatiques, musculaires et plasmatiques de la carpe (Cyprinus carpio) soumise a un jeune total et prolonge. Comparative Biochemistry and Physiology -- Part A: Physiology, 5I(1), 185193. https://doi.org/10.1016/0300-9629(75)90434-X

Boyer, P., \& Beaugelin-Seiller, K. (2002). CASTEAUR: a tool for operational assessments of radioactive nuclides transfers in river ecosystems. Radioprotection, 37(C1), 1127-1131.

Duffa, C., Antonelli, C., Vray, F., Marant, M.-J., \& Salaun, G. (2007). La base de données SYLVESTRE au service de la qualité et de l'expertise en radioécologie ā l'IRSN. Radioprotection, 42(2), 219-225.

EDF. (2014). Centrales nucléaires et environnement Prélèvements d'eau et rejets. EDP Sciences, les Ulis. 258 pp.

Elliott, J. M. (1975). The growth rate of Brown Trout (Salmo trutta L.) fed on reduced rations. Journal of Animal Ecology, 44(3), 823-842. https://doi.org/10.2307/3721 
Emmery, A., Lefebvre, S., Alunno-Bruscia, M., \& Kooijman, S. (2011). Understanding the dynamics of $\delta 13 \mathrm{C}$ and $\delta 15 \mathrm{~N}$ in soft tissues of the bivalve Crassostrea gigas facing environmental fluctuations in the context of Dynamic Energy Budgets (DEB). Journal of Sea Research, 66(4), 361-371.

Enes, P., Panserat, S., Kaushik, S., \& Oliva-Teles, A. (2009). Nutritional regulation of hepatic glucose metabolism in fish. Fish Physiology and Biochemistry, 35(3), 519-539. https://doi.org/10.1007/s10695-008-9259-5

Eyrolle, F., Lepage, H., Copard, Y., Ducros, L., Claval, D., Saey, L., Cossonnet, C., Giner, F., \& Mourier, D. (2018). A brief history of origins and contents of Organically Bound Tritium (OBT) and 14C in the sediments of the Rhône watershed. Science of the Total Environment, 643, 40-51. https://doi.org/10.1016/j.scitotenv.2018.06.074

Florence, D., \& Hartmann, P. (2003). Les rejets radioactifs et chimiques des centrales nucléaires d'EDF.

Galeriu, D., Beresford, N. A., Takeda, H., Melintescu, A., \& Crout, N. M. J. (2003). Towards a model for the dynamic transfer of tritium and carbon in mammals. Radiation Protection Dosimetry, 105(1-4), 387-390. https://academic.oup.com/rpd/articleabstract/105/1-4/387/1601784

Galeriu, D., Melintescu, A., Beresford, N. A., Crout, N. M. J., Peterson, R., \& Takeda, H. (2007). Modelling $3 \mathrm{H}$ and $14 \mathrm{C}$ transfer to farm animals and their products under steady state conditions. Journal of Environmental Radioactivity, 98(1-2), 205-217. https://doi.org/10.1016/j.jenvrad.2006.11.010

Garnier-Laplace, J., Beaugelin-Seiller, K., Gilbin, R., Della-Vedova, C., Jolliet, O., \& Payet, J. (2009). A Screening Level Ecological Risk Assessment and ranking method for liquid radioactive and chemical mixtures released by nuclear facilities under normal operating conditions. Radioprotection, 44(5), 903-908. https://doi.org/10.1051/radiopro/20095161

Jean-Baptiste, P., Fontugne, M., Fourré, E., Charmasson, S., Marang, L., \& Siclet, F. (2019). Organically bound tritium (OBT) and carbon-14 accumulation in the sediments off the mouth of the Rhône river. Environmental Earth Sciences, 78, 1-12. https://doi.org/10.1007/s12665-019-8081-y 
Klyszejko, B., Dziaman, R., \& Hajek, G. (2003). Effects of temperature and body weight on ventilation volume of common carp [Cyprinus carpio L.]. Acta Ichthyologica Et Piscatoria, 33(1), 75-81. https://www.infona.pl/resource/bwmeta1.element. agro-articlebe329450-cc6e-427c-96cc-9b293b6bf675

Kminkova, M., Winterova, R., \& Kucera, J. (2001). Fatty acids in lipids of Carp (Cyprinus carpio) tissues . Czech Journal of Food Sciences, 19(5), 177-181. https://www.agriculturejournals.cz/publicFiles/84796.pdf

Kooijman, S. A. L. M. (2010). Dynamic energy budget theory for metabolic organisation, third edition. Dynamic Energy Budget Theory for Metabolic Organisation, 3rd Edition. Cambridge University Press. 491 pp. https://doi.org/10.1017/CBO9780511805400

Le Dizès, S., Maro, D., Hébert, D., Gonze, M.-A., \& Aulagnier, C. (2012). TOCATTA: a dynamic transfer model of $14 \mathrm{C}$ from the atmosphere to soil-plant systems. Journal of Environmental Radioactivity, 105, 48-59.

McGee, E. J., Gallagher, D., Mitchell, P. I., Baillie, M., Brown, D., \& Keogh, S. M. (2004). Recent chronologies for tree rings and terrestrial archives using $14 \mathrm{C}$ bomb fallout history. Geochimica et Cosmochimica Acta, 68(11), 2509-2516. https://doi.org/10.1016/j.gca.2003.07.020

Mourlon, C., \& Vermorel, F. (2014). Results for the Chinon NPP realistic scenario using SYMBIOSE. IAEA/MODARIA/WG5.

Murai, T., Ogata, H., Kosutarak, P., \& Arai, S. (1986). Effects of amino acid supplementation and methanol treatment on utilization of soy flour by fingerling carp. Aquaculture, 56(34), 197-206.

Nagai, M., \& Ikeda, S. (1971a). Carbohydrate metabolism in fish. 1. Effects of starvation and dietary composition on the blood glucose level and the hepatopancreatic glycogen and lipid contents in carp. Bulletin of the Japanese Society of Scientific Fisheries, 37(5), $404-409$.

Nagai, M., \& Ikeda, S. (1971b). Carbohydrate metabolism in fish. 2. Effect of dietary composition on metabolism of glucose-6-14C in carp. Bulletin of the Japanese Society of Scientific Fisheries, 37(5), 410-414. 
Otlet, R. L., Walker, A. J., Fulker, M. J., \& Collins, C. (1997). Background carbon-14 levels in UK foodstuffs, 1981-1995, based upon a 1992 survey. Journal of Environmental Radioactivity, 34(1), 91-101. https://doi.org/10.1016/0265-931X(96)00001-X

Pecquerie, L., Nisbet, R. M., Fablet, R., Lorrain, A., \& Kooijman, S. A. L. M. (2010). The impact of metabolism on stable isotope dynamics: a theoretical framework. Philosophical Transactions of the Royal Society of London B: Biological Sciences, 365(1557), 3455-3468.

Ranson, S. (2003). L'alimentation de la Carpe (Cyprius carpio) dans son biotope et en élevage. Doctoral dissertation, École vétérinaire de Maisons-Alfort. 120 pp.

Roussel-Debet, S. (2014). Données utiles à l'interprétation des mesures de carbone 14 en milieu terrestre. Radioprotection, 49(1), 49-54. https://doi.org/10.1051/radiopro/2013080

Roussel-Debet, S., Gontier, G., Siclet, F., \& Fournier, M. (2006). Distribution of carbon 14 in the terrestrial environment close to French nuclear power plants. Journal of Environmental Radioactivity, 87(3), 246-259. https://doi.org/10.1016/j.jenvrad.2005.12.002

RStudio, T. (2020). RStudio: integrated development for R. RStudio, Inc. Boston.

Saito, H., Hirano, M., \& Shigeoka, T. (1994). Uptake, distribution, metabolism and excretion of Tebufenpyrad by Carp, Cyprimus carpio. Journal of Pesticide Sciences, 19, 93-101.

Sheppard, S. C., Ciffroy, P., Siclet, F., Damois, C., Sheppard, M. I., \& Stephenson, M. (2006). Conceptual approaches for the development of dynamic specific activity models of ${ }^{14} \mathrm{C}$ transfer from surface water to humans. Journal of Environmental Radioactivity, $87(1), 32-51$.

Shimizu, T., Hashimoto, Y., \& Fukami, J.-I. (1978). Uptake and accumulation of ${ }^{14} \mathrm{C}-$ labeled DDT and Parathion in Carp (Cyprinus carpio)*. Journal of Environmental Radioactivity, 3, 311-314.

Siclet, F. (2001). Transfert jusqu'a l'estuaire des radionucléides rejetés par les CNPE du bassin de la Loire. Hydroécologie Appliquée, 13, 43-83. 
Siclet, F., Luck, M., Le Dortz, J. G., Damois, C., Ciffroy, P., Hendrickx, F., \& Courivaud, J. R. (2002). Radionuclides concentrations in the Loire river system resulting from routine discharges of five nuclear power plants: assessment of dose to man. Radioprotection, 37(4), 399-410.

Smith, J. T. (2006). Modelling the dispersion of radionuclides following short duration releases to rivers: Part 2. Uptake by fish. Science of the Total Environment, 368(2), 502518.

Stephenson, M., Motycka, M., \& Schwartz, W. J. (1994). Carbon-14 activity in the water, sediments and biota of Lakes 226 North, 226 South and 224. Experimental Lakes Area, 1989 to 1994. Atomic Energy of Canada Limited Report, TR-364, COG-94-97.

Tjeerdema, R. S., \& Crosby, D. G. (1988). Comparative biotransformation of molinate (ordram $®$ ) in the white sturgeon (acipenser transmontanus) and common Carp (cyprinus carpio). Xenobiotica, 18(7), 831-838. https://doi.org/10.3109/00498258809041721

UNSCEAR (United Nations Scientific Committee on the Effects of Atomic Radiation), 2000. Sources and effects of ionizing radiation. Report to the General Assembly, with Scientific Annex, vol. 1. United Nations, New York.

UNSCEAR (United Nations Scientific Committee on the Effects of Atomic Radiation), 2008. Sources and Effects of Ionizing Radiation. Report to the General Assembly, with Scientific Annex, vol. 1. United Nations, New York.

Velisek, J., Sudova, E., Machova, H., \& Svobodova, Z. (2009). Effects of sub-chronic exposure to terbutryn in common carp (Cyprinus carpio L.) Ecotoxicology and Environmental Safety, 73(3), 384-390. https://doi.org/10.1016/j.ecoenv.2009.10.005 


\section{Figure captions}

475 Figure 1. Changes in water ${ }^{14} \mathrm{C}$ activity over time, due to absorption of dissolved radiolabelled 476 arginine measured in $8 \mathrm{~L}$-aquaria with 1 fish or no fish, and expressed as percent of mean activity on Day 0. Symbols and error bars represent mean \pm standard deviation. Dotted lines represent linear regressions, with statistical significance of slopes $(n=24$ and p.c. $<0.001 * * *$ each time; brackets indicate that the homogeneity assumption is not validated). Two-factor ANOVA $(n=48$, see SI Table S2A for details): significant effects of Days $($ p.c. $<0.001)$, Fish (p.c. $<0.001)$ and Days $\times$ Fish $($ p.c. $<0.001)$ on water activity.

482

483

Figure 2. Changes in fish ${ }^{14} \mathrm{C}$ activity over time, due to incorporation of radiolabelled arginine, measured in different fish fraction (whole body or muscle), and expressed (A) as total activity ( $\mathrm{Bq}$ per fish) and $(\mathrm{B})$ as mass specific activity $\left(\mathrm{Bq} \mathrm{g}^{-1} \mathrm{ww}\right)$. Symbols and error bars represent mean \pm standard deviation. Dotted lines represent linear regressions, with no statistical significance of slopes ( $n=6$ and p.c. $>0.05$ each time). Two-factor ANOVA $(n=12$, see SI Table S2B for details): significant effects of Fraction on total activity $\left(\right.$ p.c. $\left.=0.0025^{* *}\right)$ and mass specific activity (p.c. $\left.=0.043^{*}\right)$.

Figure 3. Changes in water ${ }^{14} \mathrm{C}$ activity over time, due to desorption of different radiolabelled sources (arginine or glucose), and expressed as percent of activity supplied in food at $0 \mathrm{~min}$. Symbols and error bars represent mean \pm standard deviation. Dotted lines represent linear regressions, with statistical significance of slopes $(n=30$ and p.c. $<0.001 * * *$ each time). Twofactor ANOVA ( $n=60$, see SI Table S3 for details): significant effects of Time $\left(\right.$ p.c. $\left.=0.016^{*}\right)$, Source $\left(\right.$ p.c. $\left.<0.001^{* * *}\right)$ and Time $\times$ Source $\left(p . c .=0.0085^{* *}\right)$ on water activity.

Figure 4. Changes in water ${ }^{14} \mathrm{C}$ activity over time, measured prior or after feeding, using radiolabelled food with (A) arginine or (B) glucose, and expressed as total activity in $8 \mathrm{~L}(\mathrm{~Bq})$. Symbols and error bars represent mean \pm standard deviation. Dotted lines represent linear regressions, with statistical significance of slopes $\left(n=24\right.$ and p.c. $<0.001^{* * *}$ each time). Twofactor ANOVA ( $n=24$, see SI Table S4A for details): significant effects of Days (p.c. < $\left.0.001^{* *}\right)$ and Feeding (p.c. $=0.0019^{* *}$ ) on water activity with arginine; significant effect of Days (p.c. $\left.=0.0037^{* *}\right)$ on water activity with glucose.

Figure 5. Changes in fish ${ }^{14} \mathrm{C}$ activity over time, due to incorporation of radiolabelled arginine (A and B) or glucose (C and D), measured in different fish fraction (whole body or muscle), 
and expressed as total activity ( $\mathrm{Bq}$ per fish) and mass specific activity $\left(\mathrm{Bq} \mathrm{g}^{-1} \mathrm{ww}\right)$. Symbols and error bars represent mean \pm standard deviation. Dotted lines represent linear regressions, with statistical significance of slopes $\left(n=12\right.$ and p.c. $=0.0016^{* *}$ and p.c. $=0.046^{*}$, p.c. $=$ $0.0013^{* *}$ and p.c. $=0.0011^{* *}$, or p.c. $<0.001 * * *$ otherwise; brackets indicate that the homogeneity assumption is not validated). Two-factor ANOVA ( $n=24$, see SI Table S4B for details): significant effects of Days (p.c. $=0.0024^{* *}$ or p.c. $=0.0043^{* *}$ ) and Fraction (p.c. $<$ $0.001 * * *$ or p.c. $<0.001 * * *)$ on total activity with arginine or glucose; significant effects of Days (p.c. $<0.001^{* * *}$ or p.c. $<0.001 * * *$ ) on mass specific activity with arginine or glucose.

Figure 6. Changes in water ${ }^{14} \mathrm{C}$ activity over time, measured during preliminary feeding or fish elimination, using radiolabelled food with (A) arginine or (B) glucose, and expressed as total activity in $8 \mathrm{~L}(\mathrm{~Bq})$. Symbols and error bars represent mean \pm standard deviation. Dotted lines represent linear regressions, with statistical significance of slopes $\left(n=44\right.$ and p.c. $<0.001^{* * *}$; $n=14$ to 29 and p.c.> 0.05 otherwise; brackets indicate that the independence assumption is not validated).

Figure 7. Changes in fish ${ }^{14} \mathrm{C}$ activity over time, due to elimination of incorporated radiolabelled arginine ( $\mathrm{A}$ and $\mathrm{B})$ or glucose $(\mathrm{C}$ and $\mathrm{D})$, measured in different fish fraction (whole body or muscle), and expressed as total activity ( $\mathrm{Bq}$ per fish) and mass specific activity $\left(\mathrm{Bq} \mathrm{g}^{-1} \mathrm{ww}\right)$. Symbols and error bars represent mean \pm standard deviation. Dotted lines represent linear regressions, with no significance of slopes ( $n=9$ and p.c. $>0.05$ each time). Two-factor ANOVA ( $n=18$, see SI Table S5 for details): significant effects of Days (p.c. $\left.=0.0037^{* *}\right)$ and Fraction $\left(p . c .<0.001^{* *}\right)$ on total activity with arginine; significant effect of Days (p.c. $=$ $\left.0.0039^{* *}\right)$ on mass specific activity with arginine; significant effect of Fraction (p.c. $<$ $0.001 * * *)$ on total activity with glucose. 


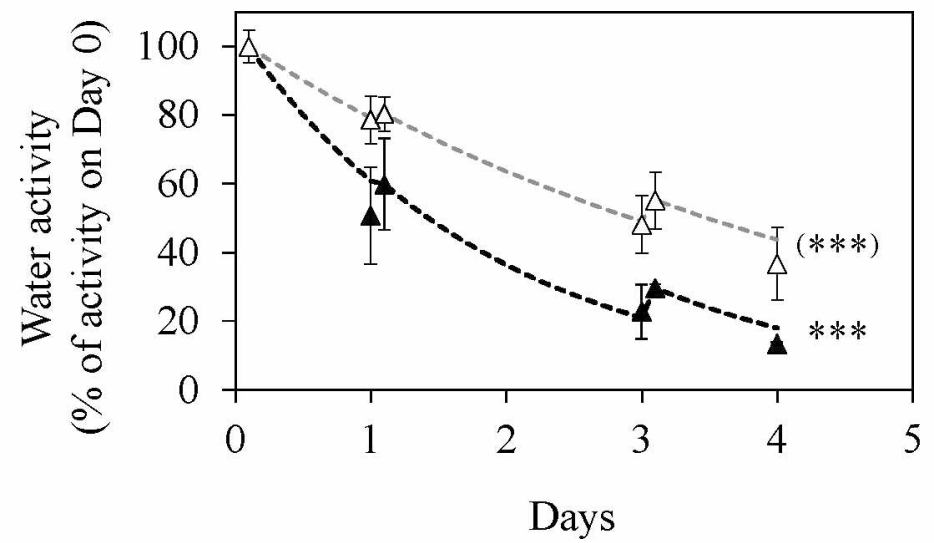

---. With fish $=-\triangle=$ No fish

Souloumiac et al, Figure 1 

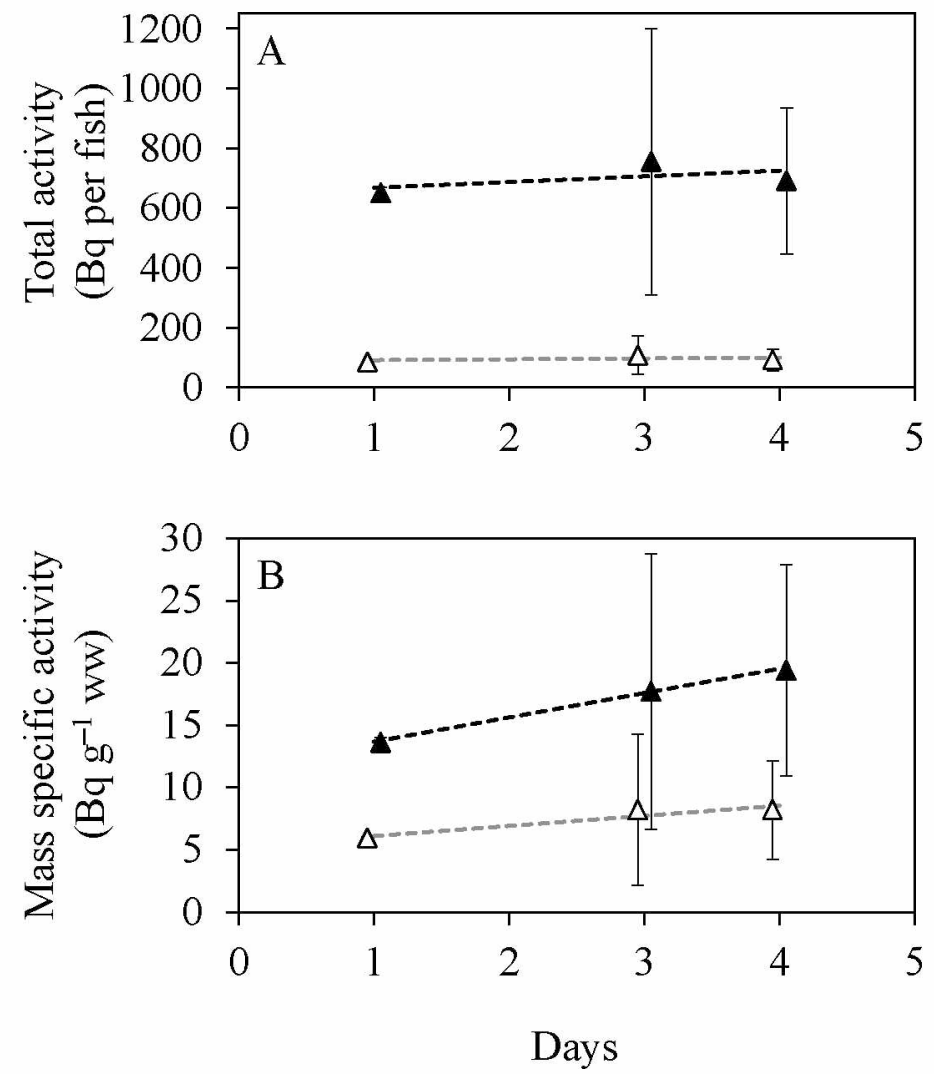

--A--. Whole body $-\Delta^{--=}$Muscle

Souloumiac et al, Figure 2 


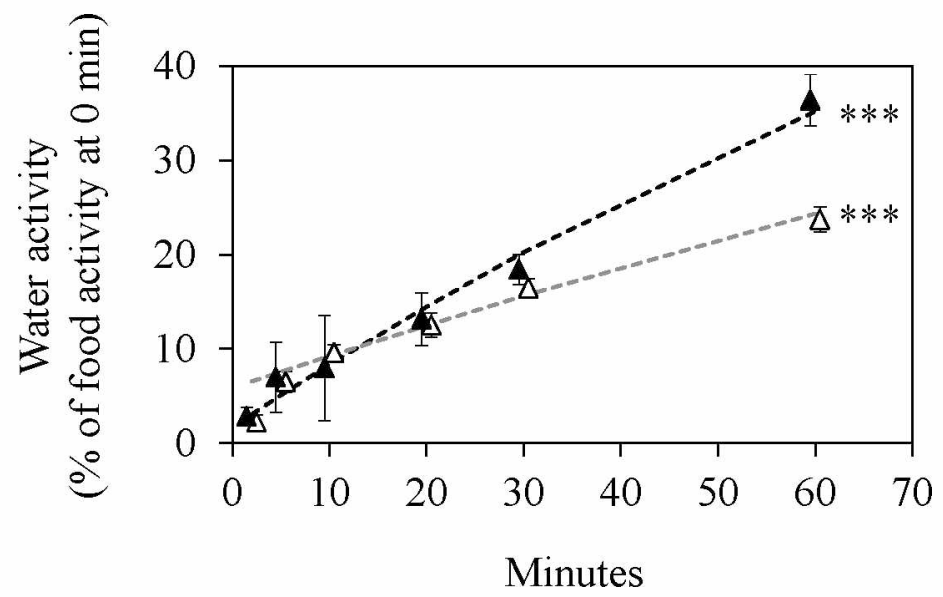

----. Arginine

$=-\triangle=-$ Glucose

Souloumiac et al, Figure 3 

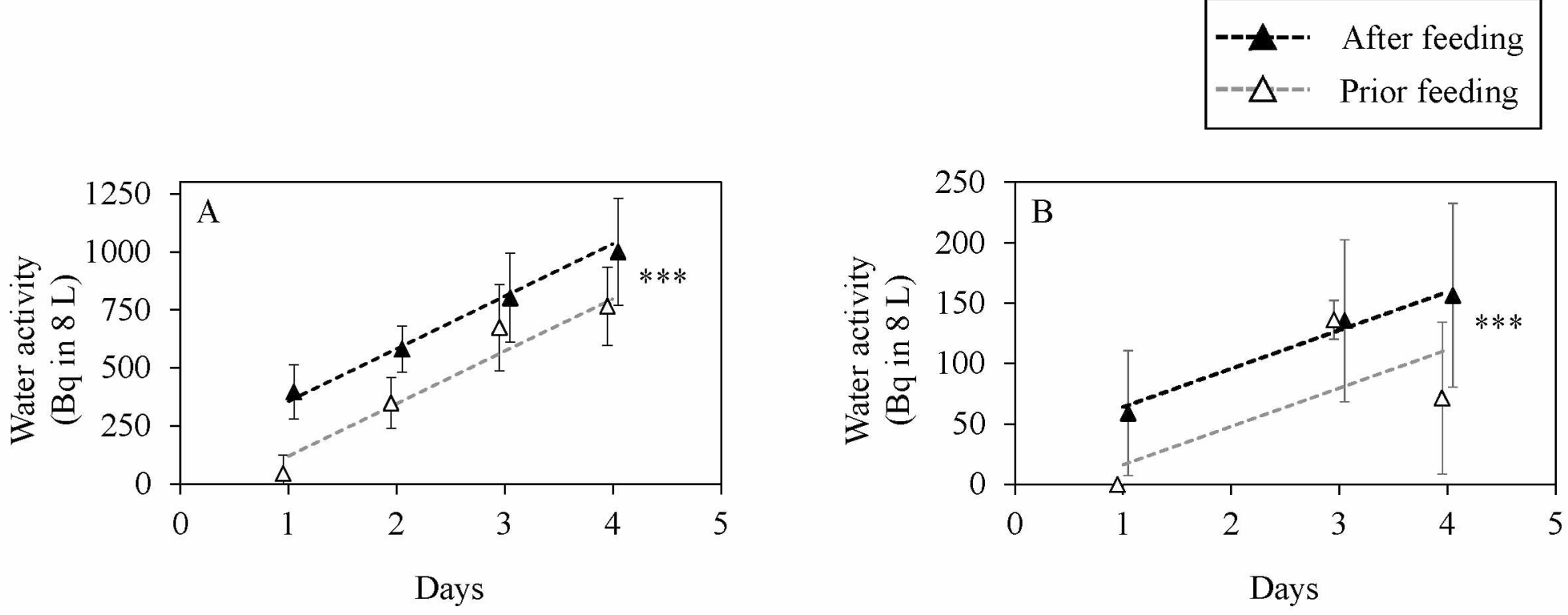

Souloumiac et al, Figure 4 


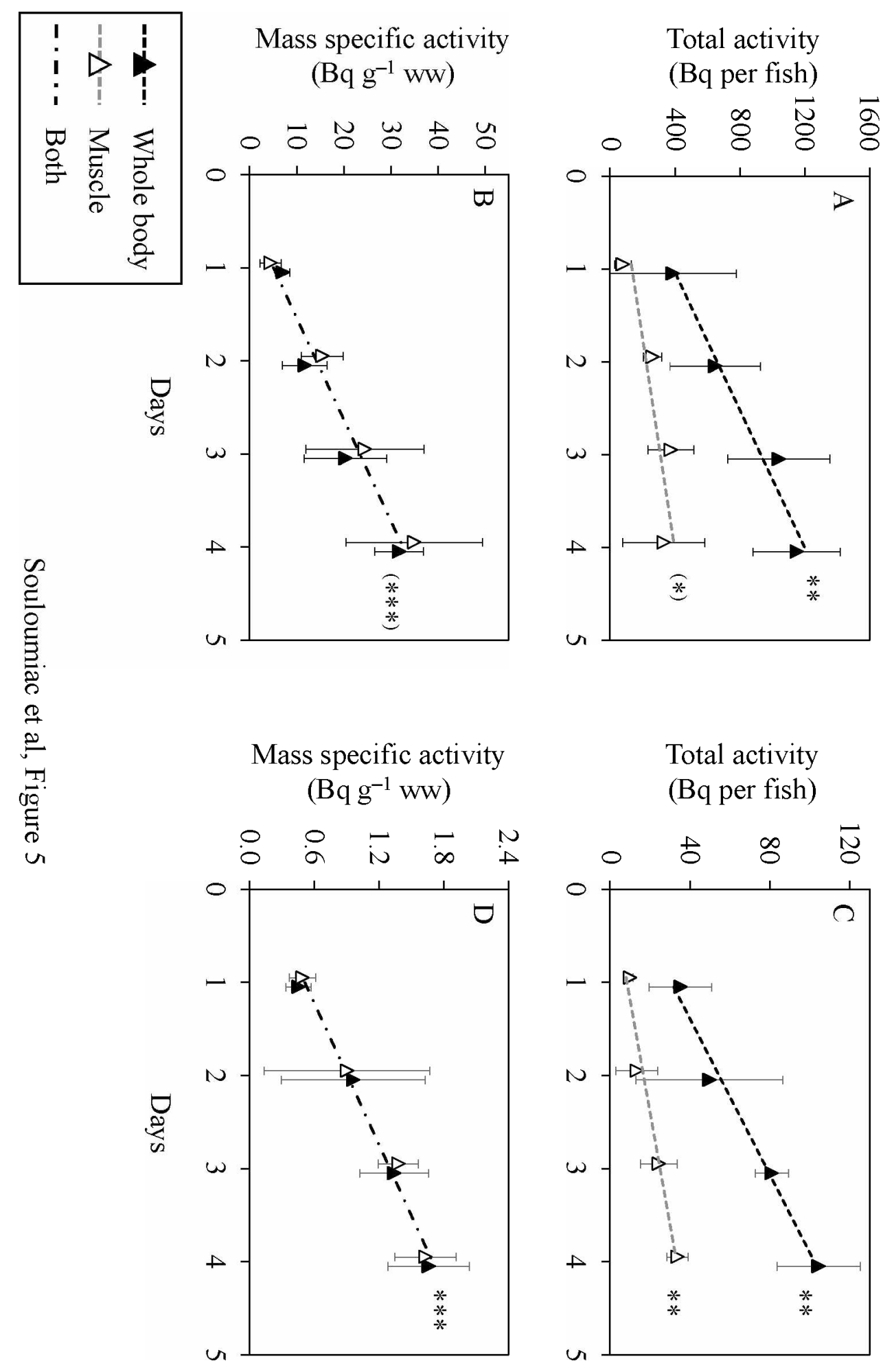




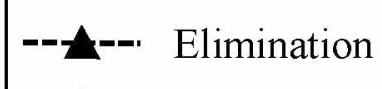

$-\triangle^{---}$Feeding
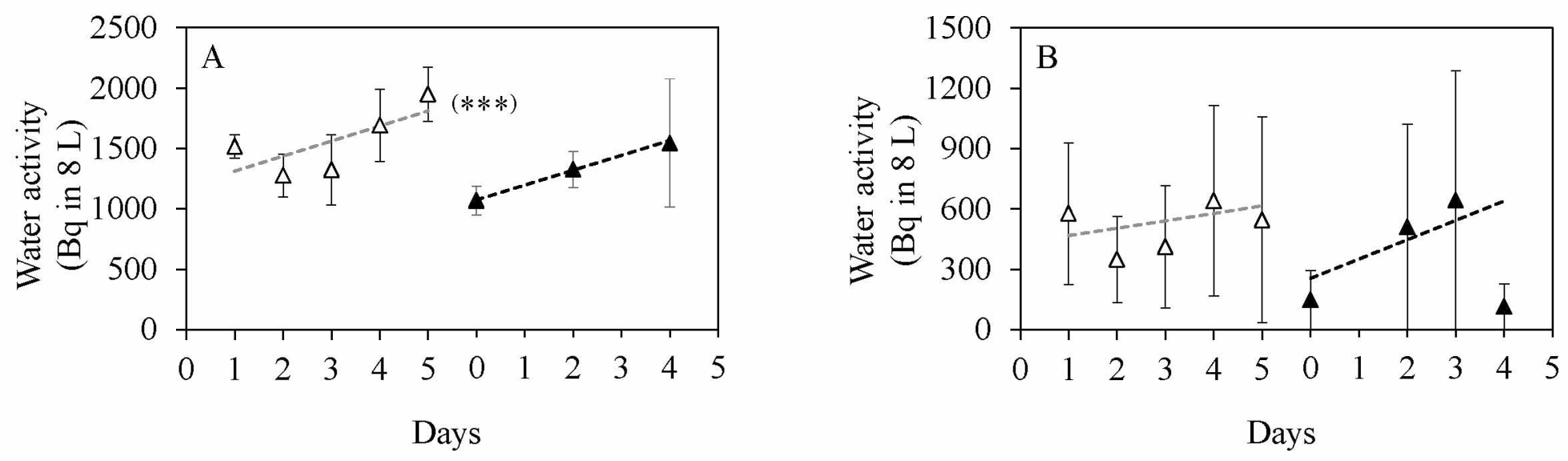

Souloumiac et al, Figure 6 
